\title{
Upper atmosphere tidal oscillations due to latent heat release in the tropical troposphere
}

\author{
J. M. Forbes ${ }^{1}$, M. E. Hagan ${ }^{2}$, X. Zhang ${ }^{1}$, K. Hamilton ${ }^{3}$ \\ ${ }^{1}$ Department of Aerospace Engineering Sciences, University of Colorado, Boulder, CO, 80309 \\ ${ }^{2}$ High-Altitude Observatory, National Center for Atmospheric Research, Boulder, CO, 80307-3000 \\ ${ }^{3}$ Geophysical Fluid Dynamics Laboratory/NOAA, Princeton University, Princeton, New Jersey
}

Received: 11 October 1996 / Revised: 20 May 1997 / Accepted: 22 May 1997

\begin{abstract}
Latent heat release associated with tropical deep convective activity is investigated as a source for migrating (sun-synchronous) diurnal and semidiurnal tidal oscillations in the $80-150-\mathrm{km}$ height region. Satellite-based cloud brightness temperature measurements made between 1988 and 1994 and averaged into 3-h bins are used to determine the annual- and longitude-average local-time distribution of rainfall rate, and hence latent heating, between $\pm 40^{\circ}$ latitude. Regional average rainfall rates are shown to be in good agreement with climatological values derived from surface rain gauge data. A global linearized wave model is used to estimate the corresponding atmospheric perturbations in the mesosphere/lower thermosphere $(80-150 \mathrm{~km})$ resulting from upward-propagating tidal components excited by the latent heating. The annual-average migrating diurnal and semidiurnal components achieve velocity and temperature amplitudes of order $10-20 \mathrm{~m} \mathrm{~s}^{-1}$ and 5$10 \mathrm{~K}$, respectively, which represent substantial contributions to the dynamics of the region. The latent heat forcing also shifts the phase (local solar time of maximum) of the semidiurnal surface pressure oscillation from 0912 to $0936 \mathrm{~h}$, much closer to the observed value of $0944 \mathrm{~h}$.
\end{abstract}

\section{Introduction}

The possibility that latent heat release related to tropical cumulus convective processes may contribute significantly to excitation of the solar semidiurnal atmospheric tide was first proposed by Lindzen (1978) and Hong and Wang (1980), and further studied by Hamilton (1981a). These studies focused on the discrepancy between the

Correspondence to: J. M. Forbes

(e-mail: forbes@zeke.colorado.edu) observed (Haurwitz and Cowley, 1973) 0944-LT phase of the semidiurnal surface pressure oscillation, $S_{2}(p)$, at low latitudes and the roughly 0900-LT phase computed for the response to direct absorption of solar insolation. These studies showed that the latent heat release associated with a semidiurnal variation in rainfall of about $1.2 \mathrm{~mm} \mathrm{day}^{-1}$, with a maximum between 0230 and $0430 \mathrm{LT}$ (and 1430 and $1630 \mathrm{LT}$ ), would produce a surface pressure oscillation with about the correct amplitude and phase to resolve the discrepancy. The observed variations in rainfall appeared to be consistent with the given requirements. Hamilton (1981a) also considered the influences of diurnal rainfall and latent heat release in the diurnal component of the surface pressure oscillation, $S_{1}(p)$.

Latent heat release in the troposphere can be expected to excite various diurnal and semidiurnal vertically propagating oscillations which grow exponentially with height and are ultimately dissipated by eddy and molecular diffusion between about 80 and $150 \mathrm{~km}$. However, the studies by Lindzen (1978), Hong and Wang (1980), and Hamilton (1981a) did not consider possible implications of their results to mesosphere/ lower thermosphere dynamics. The global-scale wave model (GSWM) recently described by Hagan et al. (1995) is particularly well suited to this type of calculation, and is used here to examine the possible influences of diurnal and semidiurnal variations in tropospheric latent heat release on the dynamics of the $80-150 \mathrm{~km}$ height regime.

Recently, Hagan et al. (1997a) investigated tidal signatures associated with tropospheric latent heat release using the GSWM. They employed the heating rates of Williams and Avery (1996) and calculated upper-atmosphere wind perturbations of the order of a few to several $\mathrm{m} \mathrm{s}^{-1}$. These investigations focused exclusively on the diurnal tide, but these authors considered the effects of both migrating and nonmigrating components. They concluded that while the individual contribution of a given diurnal component due to latent heat release was of arguable importance, the 
collective effects of these perturbations were nonnegligible.

In the present study, 7 years of satellite-based threehourly cloud brightness temperature measurements are used to derive the diurnal and semidiurnal components of rainfall rate, and hence latent heat release, as a function of longitude, between $-40^{\circ}$ and $+40^{\circ}$ latitude. Consistency between these rainfall rates and those obtained from rain gauge records is demonstrated. The latent heating distributions are decomposed into harmonic components which are subsequently used to drive the GSWM. The diurnal and semidiurnal tidal oscillations throughout the atmosphere obtained from these calculations will be discussed with particular emphasis on the $80-150-\mathrm{km}$ region.

Vertical heating profiles and other GSWM parameters are provided in Sect. 2. The satellite rainfall analysis conducted for the present study is described in Sect. 3, and comparisons with rain gauge data are provided in Sect. 4. Results of the tidal calculations are discussed in Sect. 5 and conclusions are summarized in Sect. 6.

\section{Heating profile and other GSWM parameters}

The GSWM is described in Hagan et al. (1993, 1995), so only an abbreviated summary is provided here. The GSWM solves the coupled momentum, thermal energy, continuity, and constitutive equations for linearized and steady-state perturbations on a sphere from the surface to around $400 \mathrm{~km}$. In addition to the frequency and zonal wavenumber of the oscillation, one must specify the distribution of forcing and the zonally averaged background atmospheric state (winds, temperatures, pressures, densities). Herein we use April equinoctial fields for the background atmosphere as described in Hagan et al. (1995), as the diurnal tide is only weakly affected by the mean zonal winds. The latent heating profile specification is described in the following.

Although the numerical model is nonseparable in latitude and height, it is convenient to adopt a separable form for the heating distribution:

$J(z, \theta)=J_{z}(z) J_{\theta}(\theta)$.

The Hough modes characterizing the upper-level response should not be strongly sensitive to details of the vertical distribution of latent heating, but only to the ratio of vertical wavelength to the depth of heating for any given mode (Garcia and Salby, 1987). For $J_{z}(z)$ we utilize the empirical formula of Hong and Wang (1980), which is based on the work of Reed and Recker (1971) and Nitta (1972):

$J_{z}(z)=A\left\{\exp \left[-\left(\frac{z-6.5}{5.39}\right)^{2}\right]-0.23 \exp \left(\frac{-z}{1.31}\right)\right\}$

This profile shape is also consistent with a number of tropical heating profiles recently summarized by Webster and Lukas (1992). According to Hong and Wang, a value of $A=8.54 \mathrm{~mW} \mathrm{~kg}^{-1}$ corresponds to a rainfall rate of $1.6 \mathrm{~mm} \mathrm{day}^{-1}$. Using this normalization a rainfall rate of $1.0 \mathrm{~mm} \mathrm{day}^{-1}$ corresponds to a constant $A$ in Eq. 2 of $5.34 \mathrm{~mW} \mathrm{Kg}^{-1}$, with the peak heating rate near $6.5 \mathrm{~km}$.

Equation 2 in combination with the specification of the rainfall-rate distribution permits global specification of the latent heating due to tropical deep convective activity. This specification can then be used to force a dynamical model. The following two sections are devoted to such a specification of global rainfall rate.

\section{Satellite-based rainfall-rate estimates}

In the present work, to enable comparison with a large body of rain gauge data (see following section), we confine our attention to the annual mean component of rainfall rate, and the latent heating and tidal oscillations which result. In support of the "Global Precipitation Climatology Project" (Arkin and Xie, 1994; Janowiak and Arkin, 1991), satellite-based rainfall estimates are presently available for 1988-1994 in the form of pentad averages in 3-h UT (0-3 h, 3-6 h, . . 21-24 h) intervals over $2.5 \times 2.5^{\circ}$ latitude $\times$ longitude areas. Janowiak et al. (1994) describe the derivation of 3-h rainfall data averages from measurements made on board the GOES, Geostationary Meteorological Satellite, and Meteosat geostationary satellites for the period 1986-1990. The 1988-1994 data utilized in the present study are derived in the same manner (Janowiak et al., 1994), with linear interpolation applied across $50^{\circ} \mathrm{E}-90^{\circ} \mathrm{E}$ where there is a gap in satellite coverage. Interpolation across this longitude region was necessary in order to constrain the space-time decomposition; otherwise, artifical regions of enhanced diurnal and semidiurnal rainfall amplitudes were found to occur within the gap.

The raw data are IR brightness temperatures which are provided in "histogram" form of Table 1. Physically, "cold" IR brightness temperatures measured from space imply high cloud tops and deep convection in the Tropics. The rainfall estimates are based on the fact that total tropical rainfall for large spatial scales $(250 \mathrm{~km})^{2}$ is well correlated with the fractional coverage $\left(F_{c}\right)$ of cloud with $T<235 \mathrm{~K}$, leading to

rainfall rate $=F_{c}(T<235 \mathrm{~K}) \times 3 \mathrm{~mm} \mathrm{~h}^{-1}$.

Table 1. The IR brightness temperature intervals used in Janowiak et al. (1994) and in the present study

\begin{tabular}{ll}
\hline Histogram class & Temperature limits (K) \\
\hline 1 & $>270$ \\
2 & $266-270$ \\
3 & $261-265$ \\
$\cdot$ & $\cdot$ \\
$\cdot$ & $\cdot$ \\
9 & $231-235$ \\
$\cdot$ & $\cdot$ \\
$\cdot$ & $\cdot$ \\
15 & $191-200$ \\
16 & $<191$ \\
\hline
\end{tabular}


Here $F_{c}$ within a $2.5^{\circ}$ latitude $\times$ longitude grid box for a given temperature threshold is defined by

$F_{c}=\frac{N_{T<T_{M}}}{N_{\text {total }}}$,

where $N_{\text {total }}$ is the total number of pixels in a grid box and $N_{T<T_{M}}$ is the number of pixels colder than $T_{M}$.

We have averaged all the rainfall rates for 1988-1994 to obtain the annual mean three-hourly rainfall rates in each $2.5^{\circ} \times 2.5^{\circ}$ grid box, and have Fourier decomposed these values to obtain the diurnal and semidiurnal components of rainfall as depicted in Fig. 1. Note the region between $50^{\circ}$ and $90^{\circ}$ longitude where satellite data are missing. The discontinuity near $180^{\circ}$ longitude also represents a boundary between satellite data sources. The areas of enhanced rainfall coincide with well-known areas of deep convective activity (Janowiak et al., 1994; Berg and Avery, 1995; Hendon and Woodberry, 1993; Williams and Avery, 1996). These distributions obviously imply a range of eastward- and westward-propagating wave components, in addition to a stationary contribution. Previous analyses of more limited data sets (Hendon and Woodberry, 1993; Williams and Avery, 1996) concluded that the dominant zonal wavenumbers $(s)$ for the diurnal tide were $s=-5,-2,-1,0,+3$, and $s=-6,-2,+2$ for the semidiurnal tide, where $s>0$ implies eastward propagation, $s<0$ implies westward propagation, and $s=0$ corresponds to the standing oscillatory component.

We have performed space-time decomposition of the data depicted in Fig. 1 using both fast-Fourier transform (FFT) and least-squares fitting techniques, obtaining identical results. Figure 2 illustrates the annual mean latitudinal and zonal wavenumber distributions of diurnal and semidiurnal power. In the present study, we focus attention on the large migrating (or sunsynchronous) diurnal and semidiurnal components, corresponding to $s=-1$ and $s=-2$, respectively. Analysis of the nonmigrating (longitude-dependent) components will be presented in future work.

An alternative method of isolating the solar migrating component of the rainfall data and checking results from FFT and least-squares techniques, is to order and average the data in local time. The bottom panel of Fig. 3 illustrates the results of this averaging procedure. The rainfall rates depicted here represent 7-year zonal averages ordered in local time and latitude and after the diurnal mean component has been removed. The diurnal variation in rainfall varies from about -0.8 to $+1.4 \mathrm{~mm} \mathrm{day}^{-1}$ (with maximum excursions of -1.04

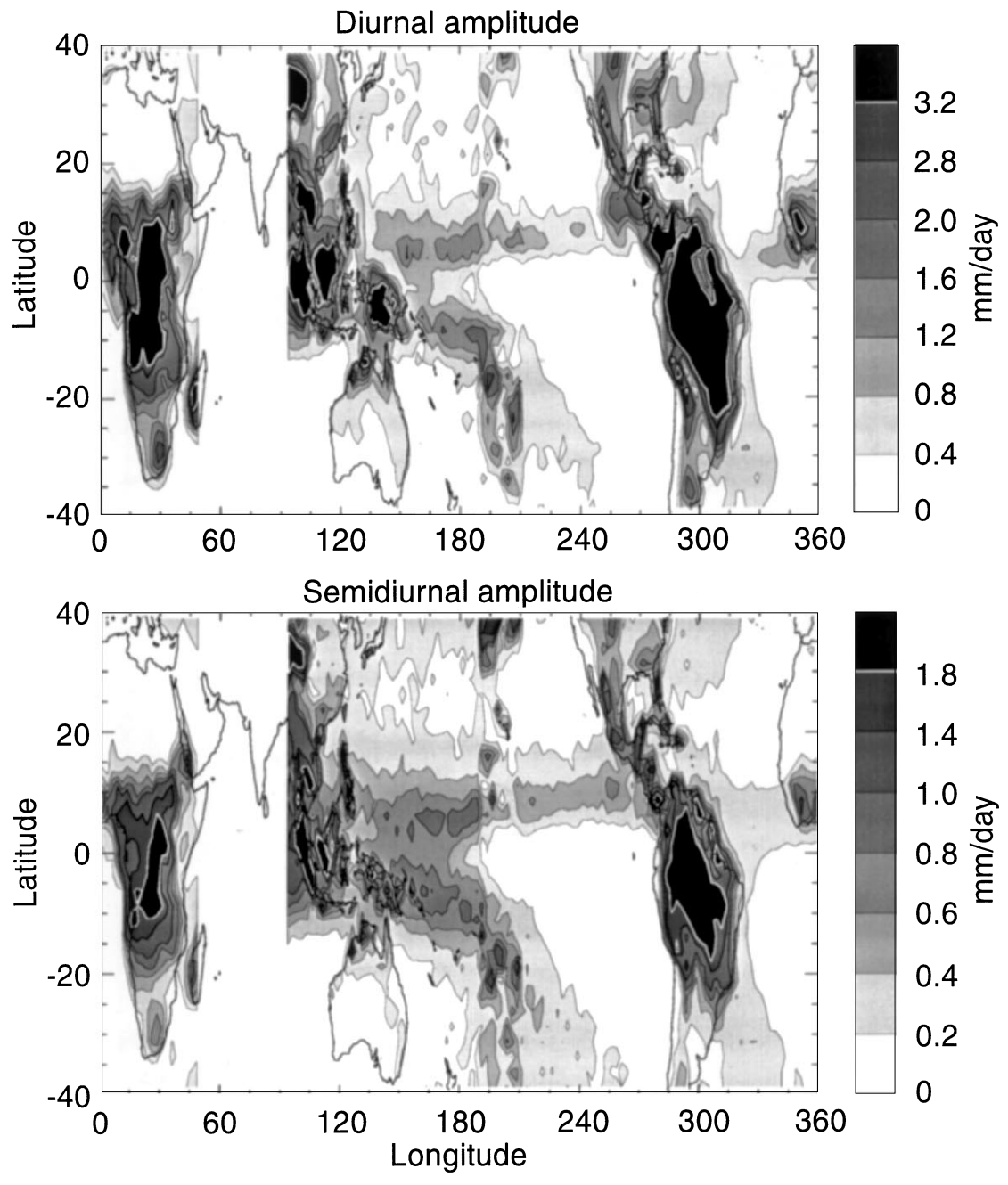

Fig. 1. Diurnal (top) and semidiurnal (bottom) harmonic components of the 7-year (19881994) annual-mean rainfall-rate distribution, as derived from satellite-based cloud brightness temperature measurements. Satellite data are not available between about $50^{\circ} \mathrm{E}$ and $90^{\circ} \mathrm{E}$ (Janowiak et al., 1994) 

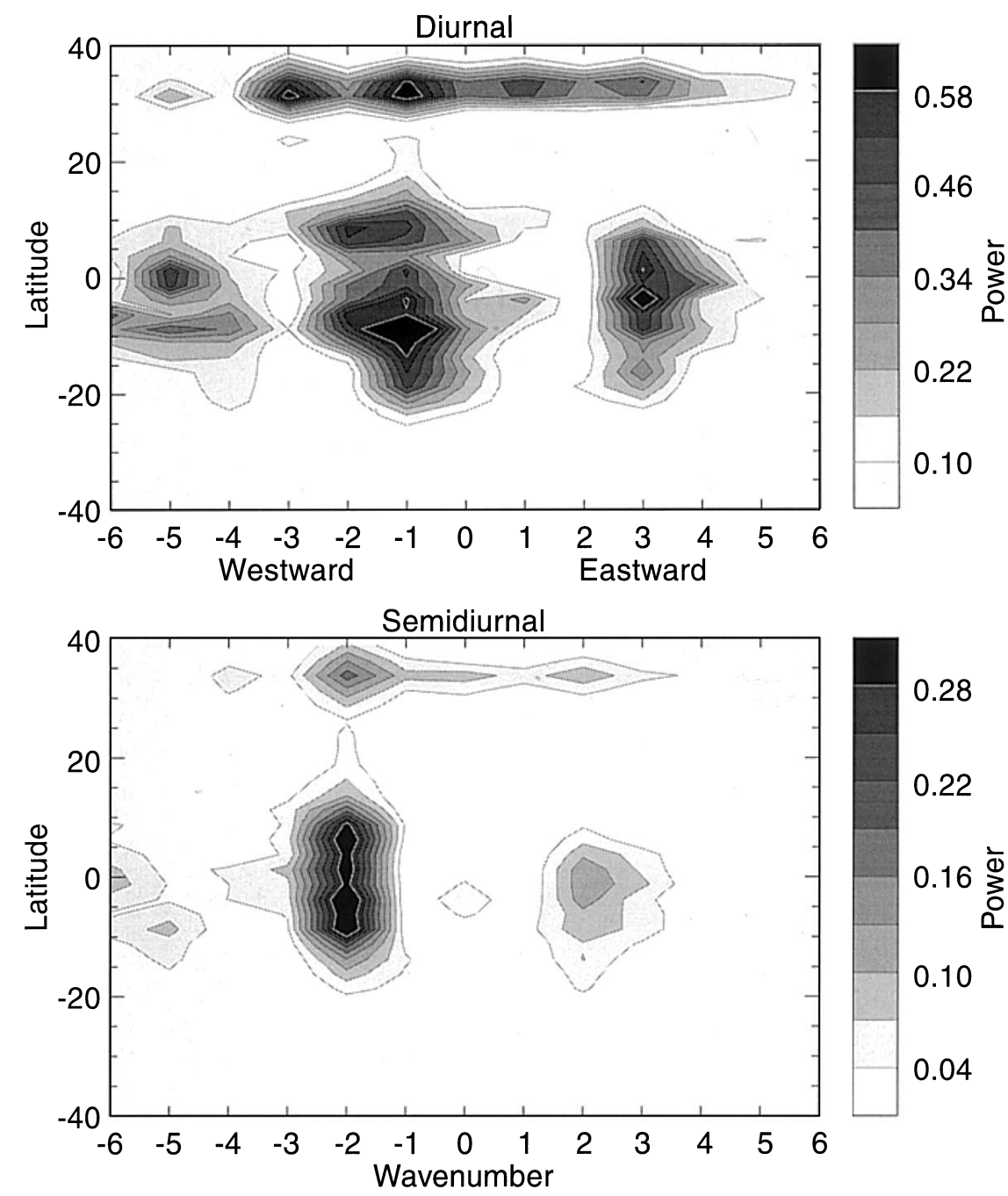

Fig. 2. Latitude and zonal wavenumber distributions of power for the diurnal (top) and semidiurnal (bottom) components of rainfall. Units are arbitrary, and are different for the two panels

and $+1.74 \mathrm{~mm} \mathrm{day}^{-1}$ ), with the maximum rainfall occurring between 1600-2000 local time. The $s=0$, or standing oscillation of the annual mean rainfall distribution is obtained by a complementary averaging procedure. That is, the data are ordered in universal time as a function of latitude. These are shown in the upper panel of Fig. 3. Comparison between the two panels in Fig. 3 reveals that the migrating rainfall oscillation exceeds that of the stationary oscillation. This is in contrast to the conclusions drawn by Hendon and Woodberry (1993) and Williams and Avery (1996) on the basis of their examination of much less data.

The lower panel of Fig. 3 provides the basic data needed to calibrate the heating rate distributions defined by Eqs. 1 and 2. Fourier decomposition in local time of these data results in the solid curves depicted in Fig. 4. Therefore, these curves represent the annual-average diurnal and semidiurnal migrating components of the rainfall rate in terms of amplitude and phase, where phase is defined as the local time of maximum rainfall. The curves in Fig. 4 represent the $J_{\theta}(\theta)$ part of the heating expression of Eq. 1, and when combined with Eq. 2 for $J_{z}(z)$ with $A=5.34 \mathrm{~mW} \mathrm{~kg}^{-1}$, the global distribution of latent heating for the migrating diurnal and semidiurnal tides is fully specified. As shown in Fig. 4, the diurnal and semidiurnal components of rainfall maximize at low latitudes at about $0.8 \mathrm{~mm} \mathrm{day}{ }^{-1}$ and $0.6 \mathrm{~mm} \mathrm{day}^{-1}$, respectively. The secondary maxima near $30^{\circ}-35^{\circ}$ latitude are apparently connected with monsoon activity in northern India and Tibet, although it should be noted that these features are influenced by interpolated values between $50^{\circ}$ and $90^{\circ} \mathrm{E}$. The corresponding phases of the migrating tidal oscillations are nearly coherent at all latitudes, maximizing near $1700 \mathrm{LT}$ for the diurnal component and 0400 (1600) LT for the semidiurnal component.

It should be noted that Janowiak et al. (1994) find the diurnal phase of fractional cloud cover over ocean areas to vary with the temperature threshold used (while cold clouds are most frequently observed over land between 1800 and 2100 LST independent of the temperature threshold). For instance, the coldest cloud-top temperatures $(T<215 \mathrm{~K})$ tend to peak between 0300 and 0600 LST over the oceans. However, the early-morning (0300-0600) events where $T<215 \mathrm{~K}$ are infrequent, and this lack of coherence diminishes their influence on the coherent tidal fields investigated here. More importantly, however, the amplitude of the diurnal cycle of 

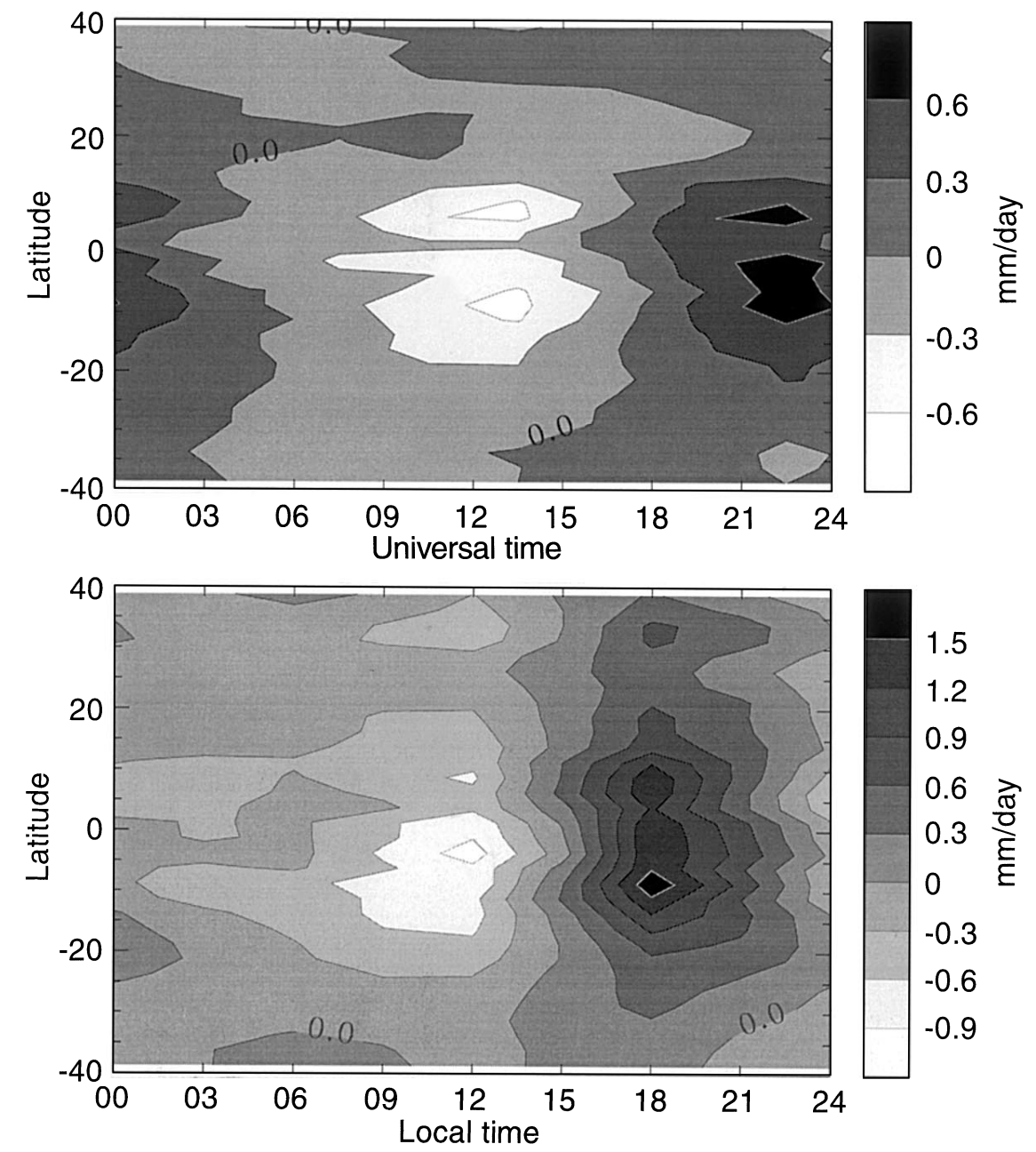

Fig. 3. 7-year (1988-1994) annual-mean distributions of the stationary and solar migrating components of rainfall rate, as derived from satellite-based cloud brightness temperature measurements. Top: universal time distribution, i.e., averaged over all local times, consisting of all the stationary wave components. Bottom: local-time distribution, i.e., averaged over all universal times (or longitudes), consisting of all those components which migrate with the apparent motion of the sun

cloud (and hence precipitation) is very weak over the ocean in comparison to that over land, and hence the phase does not significantly influence the space-time decomposition. For all these reasons any possible differences in phase of the diurnal cycle of precipitation over the oceans with respect to land areas have been neglected in the present study.

\section{Comparisons with rain gauge data}

The rainfall data used in the present analysis correspond to the compilations described in Hamilton (1981b). The stations from this data set which lie equatorward of $40^{\circ}$ latitude are enumerated in Table 2. Note that many of the data sets represent annual means covering 6-10 years or more. The stations listed in Table 2 are mostly at continental locations, consisting of a mixture of coastal and inland sites. Such a geographical distribution of stations is inadequate to derive the migrating diurnal and semidiurnal components of the rainfall rate and latent heating, since a proper longitude average must also take into account oceanic measurements. In addition, there are important local effects related to mountains and land/sea interactions. Oceanic rain gauge data are very sparse, necessitating the use of satellite-based data for global studies. Nevertheless, it is important to ascertain the consistency of satellite-based rainfall-rate estimates with those determined from rain gauge data. That is the purpose of this section.

The data in Table 2 fall into five main geographical areas defined in Table 3 . The region between $50^{\circ}$ and $90^{\circ} \mathrm{E}$ is excluded since it consists mainly of interpolated data.

Although previous studies have calibrated total rainfall rates, no study to date has attempted to establish consistency between the harmonic components of rainfall rate obtained from satellite-based measurements, and those inferred from rain gauge data. Such a comparison is summarized in Fig. 5, which illustrates the regional vector averages of the mean, diurnal, and semidiurnal rainfall rates for both rain gauge data (ordinate) and satellite-based determinations (abscissa). Points falling on the diagonal lines imply a close match between the satellite- and ground-based rainfall estimates. We note that apart from a few exceptions, the agreement in both amplitude and phase is quite good. This favorable comparison serves to underscore the credibility of the satellite-based rainfall estimates depicted in Figs. 1, 3, and 4, and which are used to calibrate the latent heating rates that drive the tidal motions in the GSWM. 

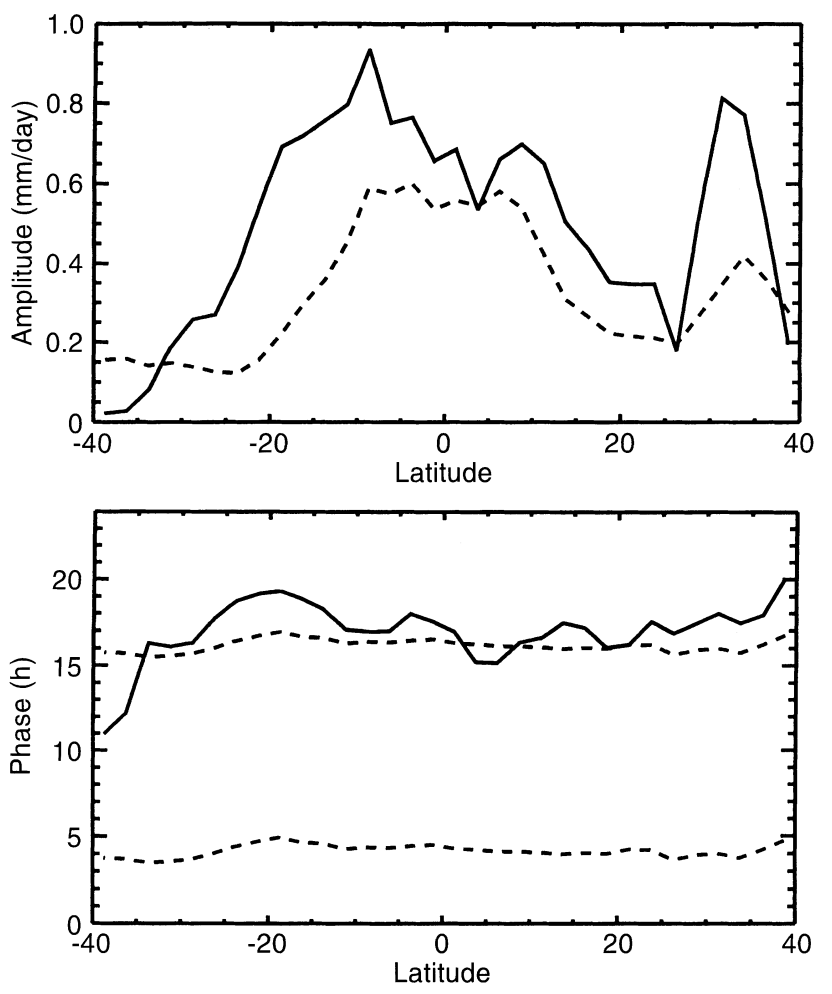

Fig. 4. Amplitudes (top) and phases (bottom) of the diurnal (solid line) and semidiurnal (dashed line) variations in rainfall, as a function of latitude. These curves correspond to the 7-year annual- and longitudemean rainfall-rate distribution, derived from Fourier decomposition (in local time) of the data presented in the bottom panel of Fig. 3. (Longitude mean in this context implies that part of the rainfall-rate distribution that migrates with the apparent motion of the sun.) These rainfall rates serve as the normalization factor $A$ in Eq. 2 for the diurnal and semidiurnal latent heating rates

\section{Results}

Tidal fields calculated with the GSWM are depicted in Fig. 6 for the diurnal harmonic and Fig. 7 for the semidiurnal harmonic. The diurnal wind fields achieve amplitudes of the order of $10-15 \mathrm{~m} \mathrm{~s}^{-1}$ and approach $25 \mathrm{~m} \mathrm{~s}^{-1}$ for the zonal (bottom left) and meridional (top left) components, respectively, maximizing near 100-km altitude and $20^{\circ}-30^{\circ}$ latitude. Temperature oscillations (bottom right) maximize at about 5-8 K near $110 \mathrm{~km}$ over the equator. These wind and temperature results are an order of magnitude larger than the migrating diurnal amplitudes associated with the forcing of Williams and Avery (1996) (see also Hagan et al., 1997a).

The phase structure for the northward wind component (Fig. 6, top right) is vertically propagating in character, with a vertical wavelength of order $25-30 \mathrm{~km}$. Similar phase structures apply to the other diurnal tidal fields. The overall latitudinal and vertical structures depicted in Fig. 6 are very similar to those which typify the diurnal oscillations associated with insolation absorption by tropospheric water vapor (Hagan et al., 1995; Hagan, 1996). This is expected, due to the similarities in latitude and vertical distributions of latent heating and water-vapor heating in the troposphere. The primary propagating component that is excited is the $(1,1)$ mode. Moreover, higher-order propagating modes have much shorter vertical wavelengths and hence are severely damped by turbulent dissipation. However, the heating rates due to these sources are approximately in quadrature, with water-vapor absorption maximizing near noon and the latent heat release occurring in early evening. This latter difference, along with any phase or vertical wavelength departures connected with details in the respective vertical heating profiles, will complicate the total fields resulting from superposition of these two contributions aloft.

The corresponding semidiurnal tidal fields are depicted in Fig. 7. The zonal and meridional wind oscillations achieve peak amplitudes of order $10-20 \mathrm{~m} \mathrm{~s}^{-1}$ between 110 and $130 \mathrm{~km}$ and between $55^{\circ}$ and $75^{\circ}$ latitude. Vertical wavelengths of order $25-45 \mathrm{~km}$ are evident in the meridional phase contours (top right). Temperatures

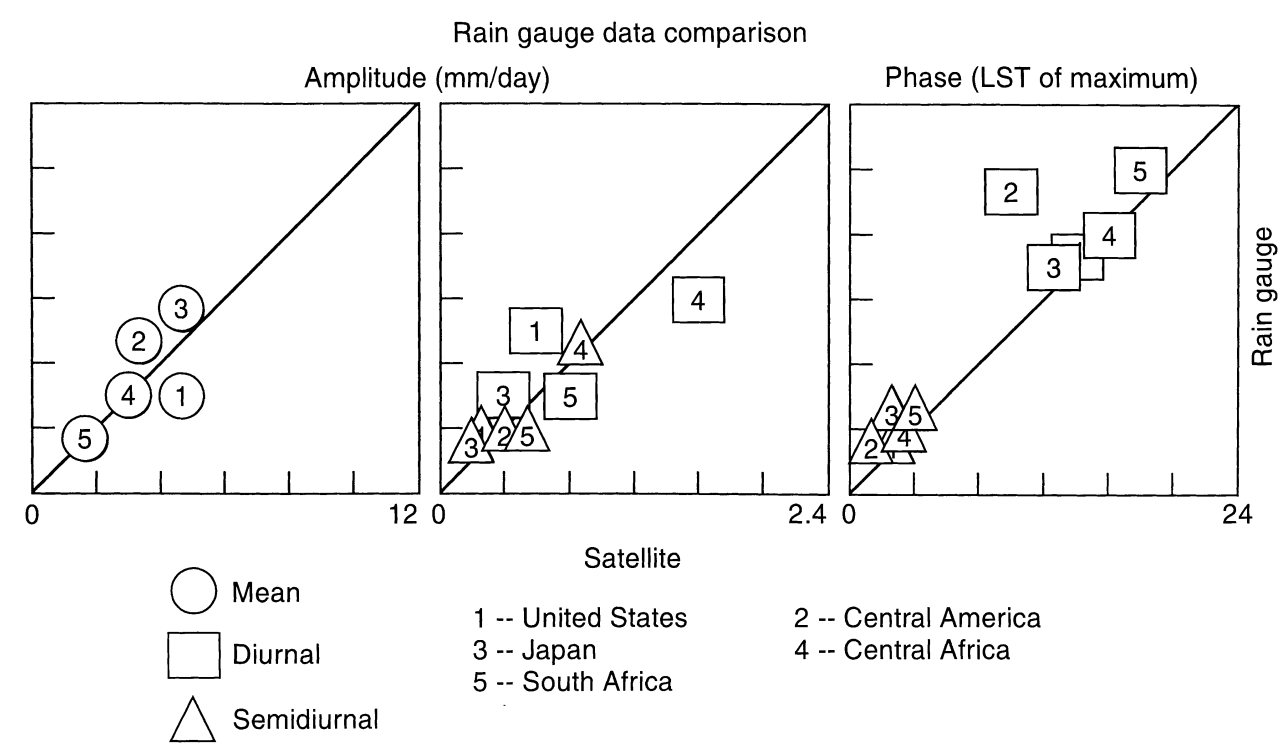

Fig. 5. Comparison of regionalmean components (diurnal mean, diurnal, and semidiurnal) of rainfall rate obtained from satellite-based cloud brightness temperature measurements, and from ground-based rain gauge instruments. The former represent 7-year means, and the latter usually represent $>10$-year means, as indicated in Table 2. The five geographic regions chosen for comparison are defined in Table 3. 
Table 2. Rain gauge data. Ro is the mean value of rainfall rate in $\mathrm{mm} \mathrm{day}^{-1} ; \mathrm{R} 1$ and $\mathrm{R} 2$ are the diurnal and semidiurnal amplitudes, and $\mathrm{P} 1$ and P2 are the diurnal and semidiurnal phases (local times of maxima), respectively. Latitude (lat), longitude (lon) and number of years (yrs) of data are given for each station. Some stations only had data during summer months, or months centered around summer; the number of months in these cases is listed under the column labeled mo (* assumes $1500 \mathrm{~mm}$ of rainfall per annum)

\begin{tabular}{|c|c|c|c|c|c|c|c|c|c|}
\hline Station & lat & lon & mo & $y r s$ & $R o$ & $R 1$ & $P 1$ & $R 2$ & $P 2$ \\
\hline Springfield, USA & 39.8 & -89.0 & & 19 & 2.7 & 0.57 & 1.6 & 0.15 & 4.5 \\
\hline Denver, USA & 39.7 & -105.0 & & 20 & 1.09 & 0.85 & 18.1 & 0.26 & 5.4 \\
\hline Topeka, USA & 39.0 & -91.7 & & 19 & 2.09 & 0.66 & 0.1 & 0.27 & 6.0 \\
\hline Nango, JP & 36.6 & 138.2 & & 2 & 7.39 & 1.87 & 18.3 & 1.03 & 6.1 \\
\hline Nashville, USA & 36.1 & -86.7 & & 17 & 3.11 & 0.27 & 15.7 & 0.43 & 3.1 \\
\hline Knoxville, USA & 36.0 & -83.9 & & 27 & 3.18 & 0.20 & 14.1 & 0.41 & 4.8 \\
\hline Tokyo, JP & 35.7 & 139.8 & & 7 & 3.94 & 0.24 & 3.3 & 0.36 & 3.9 \\
\hline Fort smith. USA & 35.4 & -94.4 & & 20 & 2.41 & 0.03 & 3.1 & 0.11 & 4.2 \\
\hline Oklahoma City, USA & 35.4 & -97.6 & & 25 & 2.19 & 0.37 & 1.4 & 0.20 & 5.9 \\
\hline Osaka, JP & 34.6 & 135.5 & & 2 & 11.52 & 2.25 & 14.9 & 0.29 & 7.6 \\
\hline Hiroshima, JP & 34.4 & 132.4 & & 2 & 4.99 & 1.38 & 7.4 & 0.61 & 5.6 \\
\hline Yakayama, JP & 34.2 & 135.2 & & 2 & 4.31 & 0.58 & 14.3 & 0.14 & 9.1 \\
\hline Los Angeles, USA & 33.9 & -118.4 & & 9 & 2.01 & 0.41 & 3.2 & 0.05 & 0.5 \\
\hline Matsuyama, JP & 33.8 & 132.8 & & 2 & 3.67 & 0.48 & 11.0 & 0.57 & 3.1 \\
\hline Rosewell, USA & 33.4 & -104.5 & & 12 & 1.21 & 0.45 & 20.4 & 0.19 & 3.5 \\
\hline Kumamoto, JP & 32.8 & 130.7 & & 2 & 4.60 & 0.91 & 13.7 & 0.61 & 3.5 \\
\hline Simla, IN & 31.1 & 77.2 & & 4 & 3.29 & 1.29 & 12.7 & 0.81 & 1.7 \\
\hline Thomasville, USA & 30.8 & -84.0 & 6 & 10 & 4.24 & 3.43 & 13.8 & 1.10 & 1.8 \\
\hline Mobile, USA & 30.7 & -80.0 & 1 & 20 & 5.88 & 4.57 & 13.5 & 1.43 & 0.8 \\
\hline New Delhi, IN & 28.6 & 77.2 & & 18 & 1.73 & 0.53 & 11.0 & 0.31 & 3.8 \\
\hline Tampa, USA & 27.9 & -82.6 & & 24 & 5.75 & 5.99 & 16.2 & 3.12 & 4.9 \\
\hline Kathmandu, IN & 27.7 & 85.2 & 4 & 11 & 9.50 & 5.90 & 23.0 & 1.15 & 1.7 \\
\hline Dibrughar, IN & 27.5 & 95.0 & & 11 & 6.70 & 5.55 & 3.1 & 1.12 & 2.7 \\
\hline N. Lakhimpur, IN & 27.2 & 94.1 & & 8 & 8.02 & 6.38 & 3.0 & 1.05 & 3.6 \\
\hline Zezpur, IN & 26.2 & 92.8 & & 7 & 4.40 & 3.52 & 2.9 & 0.35 & 4.1 \\
\hline Gauhati, IN & 26.1 & 92.8 & & 10 & 4.15 & 1.10 & 21.6 & 0.79 & 3.8 \\
\hline Jamshedpur, IN & 22.8 & 86.2 & & 18 & 3.56 & 1.89 & 16.6 & 1.18 & 4.1 \\
\hline Sagar Island, IN & 22.6 & 88.0 & & 18 & 4.36 & 1.44 & 5.7 & 0.37 & 2.7 \\
\hline Calcutta, IN & 22.5 & 88.3 & & 7 & 4.10 & 1.59 & 15.3 & 0.77 & $4.5^{*}$ \\
\hline Hong Kong & 22.3 & 114.2 & 4 & $>5$ & 11.91 & 4.65 & 7.6 & 0.15 & 9.2 \\
\hline Nagpur, IN & 21.1 & 79.1 & & 9 & 3.01 & 0.89 & 17.4 & 0.71 & 2.8 \\
\hline Bombay, IN & 18.9 & 72.8 & & 18 & 6.06 & 1.61 & 5.4 & 0.17 & 3.8 \\
\hline Poona, IN & 18.5 & 73.9 & & 10 & 1.90 & 0.77 & 19.0 & 0.46 & 4.8 \\
\hline Kingston, JAM & 17.9 & -76.8 & & 6 & 5.89 & 2.64 & 13.2 & 1.97 & 3.3 \\
\hline Mahabaleshwar, IN & 17.9 & 73.7 & & 16 & 15.98 & 2.76 & 16.7 & 2.46 & 3.9 \\
\hline Hyderabad, IN & 17.4 & 17.4 & & 18 & 2.14 & 1.32 & 20.6 & 0.30 & 3.8 \\
\hline Chorrara, CA & 14.0 & -88.7 & & 12 & 5.55 & 7.38 & 19.4 & 2.61 & 6.7 \\
\hline San Andres, CA & 13.8 & -89.5 & & 12 & 4.57 & 5.36 & 20.4 & 1.68 & 9.1 \\
\hline El Jobo, CA & 13.7 & -89.7 & & 10 & 4.44 & 3.80 & 20.5 & 1.18 & 10.4 \\
\hline San Salvador, CA & 13.7 & -89.2 & & 13 & 5.19 & 5.56 & 20.9 & 1.64 & 9.6 \\
\hline Santa Iecla, CA & 13.7 & -89.3 & & 12 & 5.06 & 4.77 & 20.6 & 1.52 & 10.0 \\
\hline Acajutla, CA & 13.6 & -89.8 & & 7 & 4.93 & 5.14 & 22.2 & 2.81 & 9.9 \\
\hline San. Cruz Porr., CA & 13.3 & -88.8 & & 12 & 4.76 & 4.72 & 21.4 & 1.69 & 10.1 \\
\hline Madras, IN & 13.0 & 80.2 & & 18 & 3.04 & 1.18 & 23.5 & 0.15 & 0.7 \\
\hline Paramakibo, SAM & 5.8 & -55.2 & & 12 & 6.01 & 4.19 & 13.5 & 3.15 & 2.0 \\
\hline Zanderij, SAM & 5.4 & -55.2 & & 2 & 5.47 & 6.39 & 15.1 & 3.85 & 3.3 \\
\hline Afobaka, SAM & 5.0 & -55.0 & & 3 & 5.40 & 6.10 & 17.0 & 2.57 & 4.1 \\
\hline Chinchina, SAM & 5.0 & -75.6 & & 3 & 2.83 & 2.10 & 12.3 & 1.01 & 3.0 \\
\hline Bagota, SAM & 4.6 & -74.1 & & 30 & 2.60 & 2.25 & 16.3 & 1.60 & 3.1 \\
\hline Kuala Lumpur & 3.1 & 101.7 & & 38 & 6.00 & 5.35 & 16.2 & 4.83 & 3.7 \\
\hline Lodwar, AF & 3.1 & 35.6 & & 7 & 0.46 & 0.33 & 9.4 & 0.04 & 7.1 \\
\hline Gulu, AF & 2.7 & 32.3 & & 15 & 4.03 & 3.08 & 19.3 & 0.98 & 4.3 \\
\hline Sipalimini, SAM & 2.0 & -56.1 & & 2 & 5.38 & 2.42 & 21.6 & 0.64 & 3.7 \\
\hline Masindi, AF & 1.7 & 31.7 & & 2 & 3.55 & 2.27 & 17.7 & 1.77 & 4.4 \\
\hline Singapor & 1.3 & 103.9 & 1 & 15 & 7.53 & 4.67 & 13.7 & 4.26 & 2.8 \\
\hline Kitale, AF & 1.0 & 35.0 & & 13 & 3.40 & 3.89 & 16.4 & 2.67 & 3.0 \\
\hline Fort Portal, AF & 0.7 & 30.3 & & 7 & 4.05 & 4.10 & 15.4 & 2.22 & 3.4 \\
\hline Torora, AF & 0.7 & 34.2 & & 7 & 4.04 & 4.79 & 17.6 & 2.95 & 4.9 \\
\hline Eldorei, AF & 0.5 & 35.3 & & 5 & 2.91 & 2.69 & 18.8 & 0.68 & 3.9 \\
\hline Jinja, AF & 0.4 & 33.2 & & 4 & 3.49 & 0.44 & 7.5 & 1.76 & 3.6 \\
\hline Kampala, AF & 0.3 & 32.6 & & 17 & 3.21 & 1.86 & 9.8 & 1.54 & 2.7 \\
\hline Mpanga, AF & 0.2 & 32.3 & & 4 & 3.71 & 2.87 & 9.9 & 1.69 & 3.6 \\
\hline Equator, AF & 0.0 & 35.5 & & 8 & 3.19 & 3.43 & 18.5 & 0.93 & 5.7 \\
\hline
\end{tabular}

For continuation please see page 1172 
Table 2. (contd.)

\begin{tabular}{|c|c|c|c|c|c|c|c|c|c|}
\hline Station & lat & lon & mo & $y r s$ & Ro & $R 1$ & $P 1$ & $R 2$ & $P 2$ \\
\hline Entebbe, AF & 0.0 & 32.4 & & 17 & 4.34 & 4.96 & 7.3 & 1.09 & 6.8 \\
\hline Nanyuki, AF & 0.0 & 37.1 & & 20 & 2.02 & 2.66 & 15.7 & 2.02 & 3.4 \\
\hline Kisumu, AF & -0.1 & 34.7 & & 24 & 3.50 & 4.69 & 19.6 & 2.36 & 6.9 \\
\hline Quito, SAM & -0.2 & -78.5 & & 10 & 3.34 & 3.06 & 17.8 & 2.39 & 3.9 \\
\hline Mold, AF & -0.2 & 35.7 & & 8 & 3.17 & 3.37 & 17.8 & 1.23 & 5.1 \\
\hline Nakuru, AF & -0.2 & 36.1 & & 14 & 2.61 & 3.22 & 16.9 & 1.96 & 4.3 \\
\hline Elburgon, AF & -0.4 & 35.8 & & 2 & 3.38 & 4.48 & 17.6 & 2.22 & 5.3 \\
\hline Kericho, AF & -0.4 & 35.3 & & 2 & 4.98 & 6.49 & 16.9 & 2.31 & 4.3 \\
\hline Garissa, AF & -0.5 & 39.6 & & 2 & 0.81 & 0.32 & 17.4 & 0.19 & 5.9 \\
\hline Mbarara, AF & -0.6 & 30.6 & & 3 & 2.49 & 1.85 & 14.6 & 0.43 & 5.5 \\
\hline Kisii, AF & -0.7 & 34.8 & & 2 & 4.64 & 6.48 & 17.5 & 3.43 & 4.7 \\
\hline Narok, AF & -1.1 & 35.8 & & 3 & 1.97 & 2.51 & 18.0 & 1.46 & 5.4 \\
\hline Kabale, AF & -1.2 & 30.0 & & 2 & 2.70 & 2.50 & 15.8 & 0.99 & 3.3 \\
\hline Eastleigh, AF & -1.3 & 36.8 & & 7 & 2.16 & 1.33 & 21.4 & 0.60 & 5.8 \\
\hline Kabete, AF & -1.3 & 36.7 & & 21 & 2.64 & 1.52 & 21.2 & 0.45 & 6.1 \\
\hline Nairobi, AF & -1.3 & 36.9 & & 6 & 2.31 & 1.21 & 20.6 & 0.82 & 4.8 \\
\hline Nairobi, AF & -1.3 & 36.7 & & 9 & 2.92 & 1.98 & 21.0 & 0.55 & 5.3 \\
\hline Nairobi, AF & -1.3 & 36.8 & & 2 & 2.37 & 1.38 & 21.7 & 0.63 & 5.6 \\
\hline Lamu, AF & -2.3 & 40.9 & & 6 & 2.28 & 1.21 & 9.9 & 0.30 & 10.4 \\
\hline Malya, AF & -3.0 & 33.5 & & 2 & 2.24 & 2.14 & 17.5 & 1.18 & 4.9 \\
\hline Lyamungo, AF & -3.2 & 37.2 & & 21 & 4.60 & 1.59 & 3.4 & 1.06 & 3.7 \\
\hline Malindi, AF & -3.2 & 40.1 & & 3 & 2.89 & 2.26 & 9.1 & 0.73 & 11.6 \\
\hline Oldeani, AF & -3.4 & 35.5 & & 2 & 2.62 & 1.49 & 2.4 & 1.11 & 3.1 \\
\hline Voi, AF & -3.4 & 38.6 & & 24 & 1.48 & 0.89 & 16.1 & 0.61 & 4.5 \\
\hline Mombasa, AF & -4.0 & 39.6 & & 16 & 2.84 & 1.63 & 8.9 & 0.23 & 0.0 \\
\hline Mombasa, AF & -4.1 & 39.7 & & 5 & 3.29 & 2.16 & 8.4 & 0.55 & 0.9 \\
\hline Mahe, AF & 4.6 & 55.4 & & 12 & 6.32 & 0.46 & 14.2 & 0.30 & 3.5 \\
\hline Kigoma, AF & -4.9 & 29.6 & & 25 & 2.68 & 2.43 & 9.1 & 0.73 & 10.4 \\
\hline Amani, AF & -5.1 & 38.6 & & 24 & 5.22 & 2.82 & 15.9 & 1.66 & 3.7 \\
\hline Ngomeni, AF & -5.1 & 38.9 & & 5 & 3.23 & 0.64 & 13.3 & 0.63 & 2.2 \\
\hline Tabora, AF & -5.1 & 32.8 & & 20 & 2.44 & 1.10 & 20.5 & 0.58 & 4.0 \\
\hline Kongwa, AF & -6.0 & 36.3 & 6 & 7 & 1.47 & 1.06 & 16.8 & 0.60 & 4.5 \\
\hline Chukmani, AF & -6.2 & 39.2 & & 11 & 3.88 & 2.98 & 8.9 & 0.60 & 11.6 \\
\hline Dodoma, AF & -6.2 & 35.8 & & 12 & 1.58 & 0.48 & 2.7 & 0.71 & 4.6 \\
\hline Kisauni, AF & -6.2 & 39.2 & & 12 & 4.27 & 3.45 & 9.2 & 0.66 & 11.1 \\
\hline Dar Es Salaam, AF & -6.8 & 39.3 & & 9 & 3.04 & 2.54 & 9.7 & 0.86 & 11.4 \\
\hline Dar Es Salaam, AF & -6.9 & 39.2 & & 9 & 3.00 & 2.32 & 11.1 & 1.12 & 0.5 \\
\hline Mbeva, AF & -8.9 & 33.5 & & 19 & 2.42 & 1.87 & 17.2 & 1.06 & 3.9 \\
\hline Salisbury, SAF & -17.8 & 31.0 & & 30 & 2.18 & 1.40 & 18.4 & 0.31 & 3.0 \\
\hline Grand Reef, SAF & -19.0 & 32.4 & & 14 & 2.18 & 1.24 & 17.1 & 0.80 & 2.9 \\
\hline Beira, SAF & -19.8 & 34.8 & & 30 & 3.62 & 2.44 & 2.9 & 1.14 & 4.2 \\
\hline Maun, SAF & -20.0 & 23.4 & & 14 & 1.38 & 0.56 & 17.4 & 0.23 & 3.0 \\
\hline Bulamayo, SAF & -20.1 & 28.6 & & 30 & 1.76 & 1.02 & 17.2 & 0.56 & 3.3 \\
\hline Windhoek, SAF & -22.6 & 17.1 & & 7 & 0.84 & 0.79 & 18.6 & 0.31 & 5.2 \\
\hline Pietersburg, SAF & -23.9 & 29.5 & & 13 & 1.38 & 0.54 & 18.0 & 0.28 & 3.6 \\
\hline Pretoria, SAF & -25.7 & 28.2 & & 13 & 2.14 & 0.84 & 20.4 & 0.31 & 5.8 \\
\hline Pretoria, SAF & -25.7 & 28.2 & & 15 & 1.89 & 0.98 & 19.7 & 0.38 & 6.3 \\
\hline Germiston, SAF & -26.2 & 28.1 & & 13 & 1.97 & 0.86 & 18.1 & 0.44 & 4.5 \\
\hline Alexander Bay, SAF & -28.6 & 16.5 & & 14 & 0.15 & 0.03 & 4.4 & 0.04 & 9.4 \\
\hline Kimberly, SAF & -28.8 & 24.8 & & 13 & 1.17 & 0.65 & 18.5 & 0.18 & 5.2 \\
\hline Bloemfontain, SAF & -29.1 & 26.2 & & 13 & 1.54 & 0.92 & 18.3 & 0.35 & 4.2 \\
\hline Durban, SAF & -29.8 & 31.0 & & 13 & 2.52 & 1.68 & 20.9 & 0.79 & 8.1 \\
\hline Durban, SAF & -30.0 & 31.0 & & 10 & 2.72 & 1.38 & 21.4 & 0.62 & 8.8 \\
\hline Beaufort West, SAF & -32.3 & 22.7 & & 10 & 0.54 & 0.32 & 17.9 & 0.23 & 4.9 \\
\hline East London, SAF & -33.0 & 27.8 & & 10 & 2.19 & 0.54 & 21.8 & 0.36 & 7.2 \\
\hline Capetown, SAF & -33.9 & 18.5 & & 11 & 1.46 & 0.35 & 3.9 & 0.10 & 8.6 \\
\hline Capetown, SAF & -34.0 & 18.6 & & 9 & 1.36 & 0.28 & 5.0 & 0.08 & 9.0 \\
\hline Port Elizabeth, SAF & -34.0 & 25.6 & & 13 & 1.60 & 0.33 & 0.6 & 0.11 & 7.4 \\
\hline Port Elizabeth, SAF & -34.0 & 25.6 & & 15 & 1.62 & 0.21 & 21.5 & 0.10 & 8.1 \\
\hline Puakura, NZ & -37.7 & 175.3 & & 9 & 3.00 & 0.26 & 16.5 & 0.34 & 4.9 \\
\hline
\end{tabular}


Table 3. Latitudinal and longitudinal regions used to bin rain gauge and cloud imagery data

\begin{tabular}{lcc}
\hline & latitude range & longitude range \\
\hline USA & $27.5^{\circ} \mathrm{N}-40.0^{\circ} \mathrm{N}$ & $80.0^{\circ} \mathrm{W}-118.0^{\circ} \mathrm{W}$ \\
Japan & $32.5^{\circ} \mathrm{N}-37.5^{\circ} \mathrm{N}$ & $130.0^{\circ} \mathrm{E}-140.0^{\circ} \mathrm{E}$ \\
Central America & $2.5^{\circ} \mathrm{S}-18.0^{\circ} \mathrm{N}$ & $55.0^{\circ} \mathrm{W}-90.0^{\circ} \mathrm{W}$ \\
Africa & $10.0^{\circ} \mathrm{S}-5.0^{\circ} \mathrm{N}$ & $30.0^{\circ} \mathrm{E}-42.5^{\circ} \mathrm{E}$ \\
South Africa & $17.5^{\circ} \mathrm{S}-35.0^{\circ} \mathrm{S}$ & $15.0^{\circ} \mathrm{E}-35.0^{\circ} \mathrm{E}$ \\
\hline
\end{tabular}

achieve amplitudes of order 5-20 K over similar altitudes as the wind fields. Amplitudes associated with all components are highest in the northern hemisphere. However, the increase in meridional wind amplitude poleward of $75^{\circ} \mathrm{N}$ is an unrealistic artifact of the current eddy diffusivity in the model (after Garcia and Solomon, 1985). When a latitude invariant profile which peaks at $200 \mathrm{~m}^{2} \mathrm{~s}^{-1}$ is used in place of the standard GSWM scheme, this artifact disappears (not illustrated).

The semidiurnal surface pressure oscillation $S_{2}(p)$ corresponding to the preceding results has an equatorial amplitude of $0.14 \mathrm{mb}$ and a phase (local solar time of maximum) of $\approx 1200 \mathrm{~h}$, as compared with $0.63 \mathrm{mb} /$ $0912 \mathrm{~h}$ for the $S_{2}(p)$ excited by $\mathrm{H}_{2} \mathrm{O}$ and $\mathrm{O}_{3}$ insolation absorption alone in the present model. For the April simulation presented here, using the annual mean latent heating, this is sufficient to shift the phase of the total oscillation (from all three sources) from 0912 to $0936 \mathrm{~h}$, much closer to the observed value of $0944 \mathrm{~h}$. This is accomplished for a peak semidiurnal rainfall rate of about $0.6 \mathrm{~mm} \mathrm{day}{ }^{-1}$, or about half that estimated by Lindzen (1978) to shift the phase from 0900 to $0944 \mathrm{~h}$ assuming a total observed equatorial $S_{2}(p)$ of order 1.1$1.2 \mathrm{mb}$. A more careful analysis of this aspect of the problem requires examination of the seasonal variations in all of the sources and their respective contributions to the surface pressure oscillation. This work is currently being pursued by the authors.

\section{Summary and conclusions}

Using satellite-based estimates of three-hourly annualaverage rainfall rates between $-40^{\circ}$ and $+40^{\circ}$ latitude, the corresponding distributions of diurnal and semidi-

GSWM migrating diurnal tidal component 7-year annual average latent heat forcing
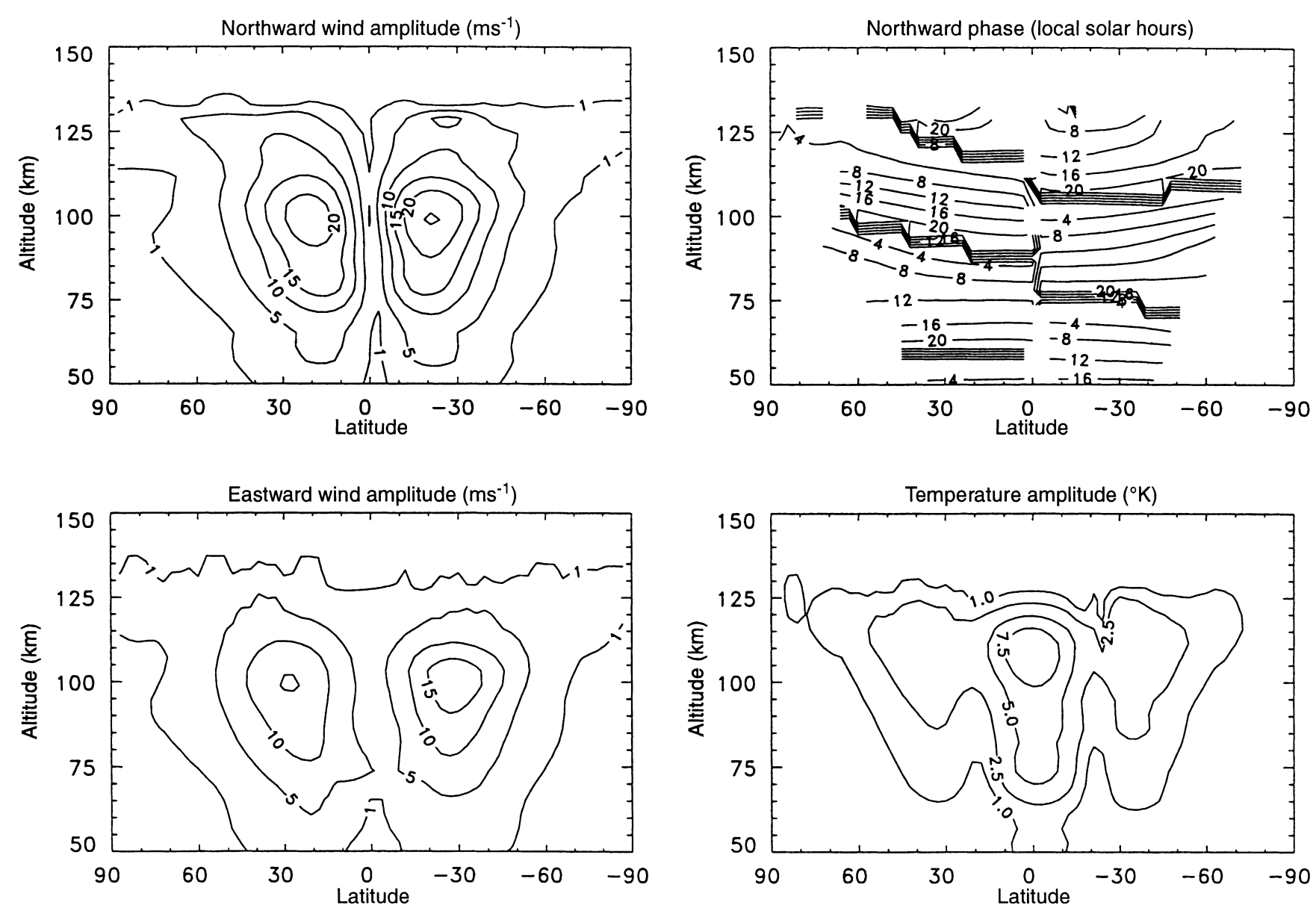

Fig. 6. Diurnal migrating tidal components calculated with the GSWM, with vertical heating specified according to Eq. 2, and latitude distribution and absolute calibration provided by the curves in Fig. 4 


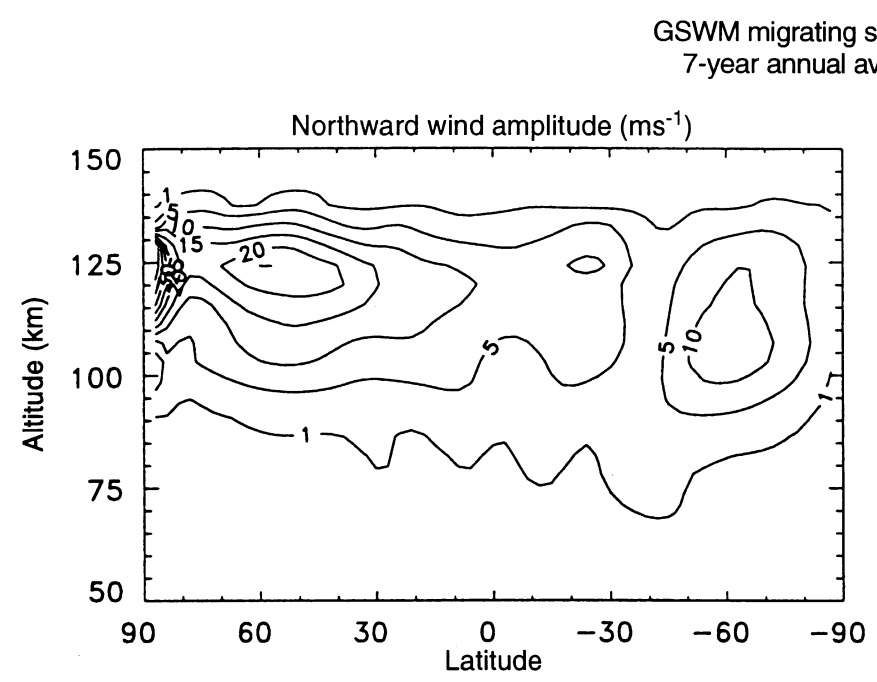

\section{rage latent heat forcing}
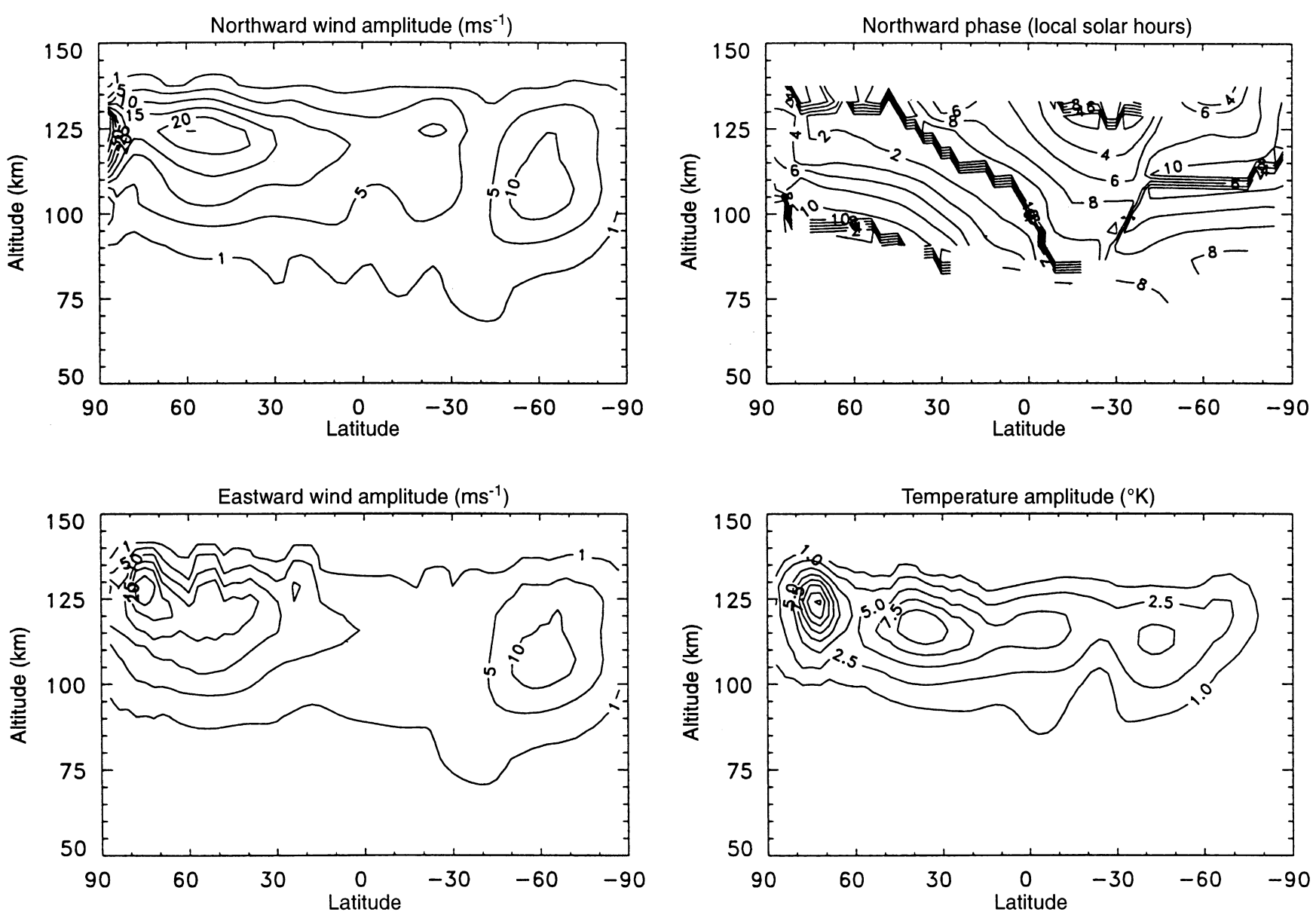

Fig. 7. As in Fig. 6, except for semidiurnal component

urnal latent heating have been determined. The heating rates are used to excite the migrating (sun-synchronous) diurnal and semidiurnal tidal oscillations in a linearized wave model. Maximum tidal amplitudes of order $10-20 \mathrm{~m} \mathrm{~s}^{-1}$ and $5-8 \mathrm{~K}$ are found to result in the atmospheric region between about 100 and $130 \mathrm{~km}$ where the waves undergo severe dissipation by eddy and molecular dissipation. These amplitudes are non-negligible compared with the total tidal fields of order 20$60 \mathrm{~m} \mathrm{~s}^{-1}$ and $10-40 \mathrm{~K}$ known to characterize this height region, and therefore must be considered in future studies of upper atmosphere tidal behavior.

The current work has focused on the annual mean component so that existing climatological rain gauge data (primarily available only for annual means) can be included in a self-contained study which compares ground- and satellite-based determinations of rainfall rate. Moreover, the primary purpose of the present work has been to demonstrate the potential importance of latent heat release in the tropical troposphere to upperatmosphere tidal dynamics, and this has been accomplished by focusing on the annual mean component. However, it must be recognized that significant spatial and temporal variations in latent heating exist which probably map into seasonal and longitudinal tidal variations as large as the annual mean component itself. These issues, including assessments of the comparative importance of other excitation sources to the tidal dynamics of the mesosphere and lower thermosphere, will be addressed by the authors in other works (i.e., Hagan et al., 1997b).

The satellite-based estimates of the migrating semidiurnal component of rainfall (dashed line in upper panel of Fig. 4) are almost a factor of two smaller than estimated by Lindzen (1978) to account for the discrepancy between the observed (0944 h) and computed $(0900 \mathrm{~h})$ phase of the surface pressure oscillation, $S_{2}(p)$. In the current work, for April conditions, the phase of $S_{2}(p)$ is $0912 \mathrm{~h}$, taking into account $\mathrm{H}_{2} \mathrm{O}$ and $\mathrm{O}_{3}$ insolation absorption aloft. Adding the annual-mean latent heating derived herein, the phase is shifted to $0936 \mathrm{~h}$, close to the observed value. This represents encouraging support for the computed latent heating rates. A more careful examination by the authors of this aspect of the problem, taking into account seasonal variations of all the heat sources, is already underway. 
Acknowledgements. J. M. Forbes was supported for this work under Grant ATM-9415874 from the National Science Foundation to the University of Colorado and M. E. Hagan was supported under NASA Grant S-97239-E to the High-Altitude Observatory, National Center for Atmospheric Research. The National Center for Atmospheric Research is sponsored by the National Science Foundation. The satellite cloud brightness temperature data used herein are products of the Global Precipitation Climatology Project (Arkin and Xie, 1994; Janowiak and Arkin, 1991). We are indebted to Bob Joyce and John Janowiak of the NOAA/ NWS/NMC Climate Analysis Center for assisting us in obtaining these data.

Topical Editor F. Vial thanks P. Dias and J. E. Janowiak for their help in evaluating this paper.

\section{References}

Arkin, P. A., and P. P. Xie, The global precipitation climatology project: first algorithm intercomparison project, Bull. Am. Meteorol. Soc., 75, 401-419, 1994.

Berg, W., and S. K. Avery, Evaluation of monthly rainfall estimates derived from the special sensor microwave/imager (SSM/I) over the tropical Pacific, J. Geophys. Res., 100, 1295-1315, 1995.

Garcia, R. R., and M. L. Salby, Transient response to localized episodic heating in the tropics. Part II: Far-field behavior, $J$. Atmos. Sci., 44, 499-530, 1987.

Garcia, R. R., and S. Solomon, The effects of breaking gravity waves on the dynamics and chemical composition of the mesosphere and lower thermosphere, J. Geophys. Res., 90, 3850-3868, 1985.

Hagan, M. E., Comparative effects of migrating solar sources on tides in the mesosphere and lower thermosphere, J. Geophys. Res., 101, 21213-21222, 1996.

Hagan, M. E., J. M. Forbes, and F. Vial, A numerical investigation of the propagation of the quasi 2-day wave into the lower thermosphere, J. Geophys. Res., 98, 23193-23205, 1993.

Hagan, M. E., J. M. Forbes, and F. Vial, On modeling migrating solar tides, Geophys. Res. Lett., 22, 893-896, 1995.
Hagan, M. E., J. L. Chang, and S. K. Avery, GSWM estimates of non-migrating tidal effects, J. Geophys. Res., accepted, 1997a.

Hagan, M. E., C. McLandress, and J. M. Forbes, Diurnal tidal variability in the upper mesosphere and lower thermosphere, Ann. Geophyicae, this issue, $1997 \mathrm{~b}$.

Hamilton, K., Latent heat release as a possible forcing mechanism for atmospheric tides, Mon. Weather Rev., 109, 3-17, 1981a.

Hamilton, K., A note on the observed diurnal and semidiurnal rainfall variations, J. Geophys. Res., 86, 12122-12126, 1981 b.

Haurwitz, B., and A. D. Cowley, The diurnal and semidiurnal barometric oscillations, global distribution and annual variation, Pure Appl. Geophys., 102, 193-222, 1973.

Hendon, H. H., and K. Woodberry, The diurnal cycle of tropical convection, J. Geophys. Res., 98, 16623-16637, 1993.

Hong, S. -S., and P. -H. Wang, On the thermal excitation of atmospheric tides, Bull. Geophys., 19, 56-84, 1980.

Janowiak, J. E., and P. A. Arkin, Rainfall variations in the tropics during 1986-1989, as estimated from observations of cloud-top temperature, J. Geophys. Res., 3359-3373, 1991.

Janowiak, J. E., P. A. Arkin, and M. Morrissey, An examination of the diurnal cycle in oceanic tropical rainfall using satellite and in situ data, Mon. Weather Rev., 122, 2296-2311, 1994.

Lindzen, R. S., Effect of daily variations in cumulonimbus activity on the atmospheric semidiurnal tide, Mon. Weather Rev., 106, 526-533, 1978.

Nitta, T., Energy budget of wave disturbances over the Marshall Islands during the years of 1956 and 1958, J. Meteorol. Soc. Japan, 50, 71-83, 1972.

Reed, R. J., and E. E. Recker, Structure and properties of synopticscale wave disturbances in the equatorial western Pacific, J. Atmos. Sci., 28, 1117-1133, 1971.

Webster, P. J., and R. Lukas, TOGA COARE: the coupled oceanatmosphere response experiment, Bull. Am. Meteorol. Soc., 73, 1377-1416, 1992.

Williams, C. R., and S. K. Avery, Diurnal nonmigrating tidal oscillations forced by deep convective clouds, J. Geophys. Res., 101, 4079-4091, 1996. 